\title{
THE INFLUENCE OF $\mathrm{CO}_{2}$ ADMIXTURES ON PROCESS IN TITAN'S ATMOSPHERIC CHEMISTRY
}

\author{
Torokova L. ${ }^{a, *}$, Mazankova V. ${ }^{a}$, Mason N. J. ${ }^{b}$, Krcma F. ${ }^{a}$, Morgan G. ${ }^{b}$, \\ MATEJCIK S. ${ }^{c}$ \\ ${ }^{a}$ Faculty of Chemistry, Brno University of Technology, Purkynova 118, 61200 Brno, Czech Republic \\ ${ }^{b}$ Department of Physical Sciences, Open University, Milton Keynes MK7 6AA, United Kingdom \\ ${ }^{c}$ Faculty of Mathematics, Physics and Informatics, Comenius University, 84248 Bratislava, Slovakia \\ * torokova@fch.vutbr.cz
}

\begin{abstract}
The exploration of planetary atmosphere is being advanced by the exciting results of the Cassin-Huygens mission to Titan. The complex chemistry revealed in such atmospheres leading to the synthesis of bigger molecules is providing new insights into our understanding of how life on Earth developed. In our experiments Titan's atmosphere is simulated in a glow discharge formed from a mixture of $\mathrm{N}_{2}: \mathrm{CH}_{4}: \mathrm{CO}_{2}$ gas. Samples of the discharge gas were analysed by GC-MS and FTIR. The major products identified in spectra were: hydrogen cyanide, acetylene and acetonitrile. The same compounds were detected in the FTIR: hydrogen cyanide, acetylene and ammonia. Whilst many of these compounds have been predicted and/or observed in the Titan atmosphere, the present plasma experiments provide evidence of both the chemical complexity of Titan atmospheric processes and the mechanisms by which larger species grow prior to form the dust that should cover much of the Titan's surface.
\end{abstract}

Keywords: atmosphere of Titan, glow discharge, GC-MS analysis and FTIR spectroscopy.

\section{Introduction}

Simple organic molecules play an important role in the formation of complex organics in planetary atmospheres. On the last decade, several lower hydrocarbons and nitriles have been confirmed in the atmosphere of Titan, the largest satellite of the Saturn. The first detailed information was brought by Voyager space mission in 1980. More important complex information about Titan atmosphere was obtained from Cassini-Huygens mission in 2005. Its atmosphere composition is principally nitrogen with $2-6 \%$ methane and some trace gases as nitriles $\left(\mathrm{HCN}, \mathrm{HC}_{3} \mathrm{~N}, \mathrm{HC}_{5} \mathrm{~N}\right.$, and $\left.\mathrm{C}_{2} \mathrm{~N}_{2}\right)$ and lower molecule hydrocarbons $\left(\mathrm{C}_{2} \mathrm{H}_{2}\right.$, $\left.\mathrm{C}_{2} \mathrm{H}_{4}, \mathrm{C}_{2} \mathrm{H}_{6}, \mathrm{C}_{3} \mathrm{H}_{8}, \mathrm{C}_{3} \mathrm{H}_{4}\right)$ as well as hydrogen [1, 2]. These compounds can be produced by low power discharges in the methane clouds 3, 4, or by dissociation of nitrogen and methane either by solar induced photolysis, photodissociation or by electron impact. The same processes generate also charged particles that are transported through the atmospheric clouds. Neutralization of these charged particles leads to high power discharges like lightning within the clouds which can induce other chemical reactions in the troposphere 51. Organic radicals produced by electron impact could also supply a significant fraction of Titan's haze and surface material [6]. Lightning activity is one of the most probable initiators of organic molecules formation on Titan lower atmosphere and has also been suggested as a mechanism for triggering the prebiotic chemistry on Earth [7, for which the lower atmosphere of Titan may be a good mimic [8 11].
The possibility of lightning on Titan is supported by theoretical models and observations of Titan's troposphere during the last decade, which indicate that methane droplets may suddenly condense and undergo vertical motions in the Titan's atmosphere 12. Most of the experiments reproduce a gas mixture close to the Titan's atmosphere, or at least to a part of its atmosphere, and then supply energy into this gas mixture to induce chemical reactions. Different plasma discharges have been shown to be good mimics to a planetary atmosphere providing insights into both physical and chemical processes of such atmosphere. Various studies of electron-molecule and ion-molecule reactions in the planetary atmosphere were presented recently. Namely results obtained by corona discharge were presented in [9-13, by DBD discharge in [14], by glow discharge in 15-17, by microwave discharge in [18, and by RF discharges in [10, 19, 20. However, the mechanisms of such organic chemistry are still unclear.

\section{Experiment}

The experimental setup schematic drawing is shown in Figure 1. The special high vacuum stainless steel reactor was constructed for our experiments to prevent any oxygen contamination during the experiments. Nitrogen and methane flows were automatically controlled by Bronkhorst controllers. The measurements were carried out at total gas flows $100 \mathrm{sccm}$ at atmospheric pressure and laboratory temperature. The discharge electrode system had the standard config- 
uration of the gliding arc discharge. The discharge was formed in the stable abnormal glow regime, and plasma was occurred between the electrodes at their shortest distance of $2 \mathrm{~mm}$ in the form of a plasma channel of $1 \mathrm{~mm}$ in its diameter. The reactor chamber volume was 0.5 l. The discharge was supplied by a DC stabilized HV source. Discharge breakdown voltage was $5500 \mathrm{~V}$, a stable plasma channel was operating at $400 \mathrm{~V}$ at current of $30 \mathrm{~mA}$ during all presented experiments. The measurements were performed for different $\mathrm{N}_{2}: \mathrm{CH}_{4}$ ratios in the range from $1 \%$ to 3 $\%$ of methane in nitrogen (both gases having quoted purities of $99.995 \%$ ) and admixture 1, 2 and $3 \%$ of carbon dioxide $\left(\mathrm{CO}_{2}\right)$. The exhaust gas was sampled using the cold trap technique. The liquid nitrogen stainless steel trap (diameter of $15 \mathrm{~mm}$, length of 165 $\mathrm{mm}$, the total volume of $116 \mathrm{~cm}^{3}$ ) was mounted at the outlet of the reactor, as it is shown in Figure 1. as a side removable arm. The sampling time was 5 min and all gas products were subsequently analysed by GC-MS. The sampling efficiency closed to $100 \%$ was confirmed by in situ FTIR done behind the sampling point (see description of experimental device). Sampling time was adjusted based on preliminary experiments to avoid saturation at GC-MS measurements.

\section{Results}

The chromatogram given in Figure 2 corresponding to experiment at nitrogen, methane and carbon dioxide are shown as typical examples. All the peaks have been identified using their retention time in the sequence and their mass spectra using the program MSD Chemistry with the NIST MS library [21]. The peaks corresponding to nitrogen, methane and carbon dioxide as the original gas mixture were recorded at retention times under 2 minutes and thus they are not depicted in Figure 2.

The other peaks of the highest intensity in these chromatograms can be attributed to lower hydrocarbons and nitrile compounds. The dominant peak corresponds to hydrogen cyanide $(\mathrm{HCN})$, the second dominant peak is acetylene $\left(\mathrm{C}_{2} \mathrm{H}_{2}\right)$ and the third main product is acetonitrile $\left(\mathrm{CH}_{3} \mathrm{CN}\right)$. Other abundant determined products were ethane $\left(\mathrm{C}_{2} \mathrm{H}_{6}\right)$, ethylene $\left(\mathrm{C}_{2} \mathrm{H}_{4}\right)$, cyanogen $\left(\mathrm{C}_{2} \mathrm{~N}_{2}\right)$, propenenitrile $\left(\mathrm{C}_{2} \mathrm{H}_{3} \mathrm{CN}\right)$, and propanenitrile $\left(\mathrm{C}_{2} \mathrm{H}_{5} \mathrm{CN}\right)$. A lot of nitriles, many hydrocarbons, and even aromatic compound, have been detected from the analysis of all obtained chromatogram. No oxygen containing compounds were detected because of our special high vacuum reactor preserved any oxygen contamination. The results for selected $\mathrm{C}_{2}$-hydrocarbons (ethane, ethylene and acetylene) and nitriles (hydrogen cyanide, acetonitrile and cyanogen) are shown in 1 The dominant hydrocarbon was acetylene and its amount increased nearly directly proportionally to the carbon dioxide concentration. Ethane and ethylene show the similar trend of relative intensity. Relative intensities of hydrogen cyanide, acetonitrile and cyanogen as the main detected compounds are depicted on carbon dioxide concentration in the gas mixture again at both total gas flows. These compounds present various chemical structures with different number of carbon and nitrogen atoms.

A typical FTIR spectrum showing the products formed in the nitrogen discharge fed by $1 \%$ of $\mathrm{CH}_{4}$ and $1 \%$ of $\mathrm{CO}_{2}$ is shown in Figure 3 . Similar spectra were observed for other $\mathrm{N}_{2}: \mathrm{CH}_{4}: \mathrm{CO}_{2}$ ratios. Hydrogen cyanide (HCN) was found to be the most abundant product at wavenumbers of $1430 \mathrm{~cm}^{-1}$ and of $720 \mathrm{~cm}^{-1}$. It is in agreement with [17]. Ammonia $\left(\mathrm{NH}_{3}\right)$ was identified at $966 \mathrm{~cm}^{-1}$ which was surprising because ammonia was not detected in previous experimental studies. The other major products were acetylene $\left(\mathrm{C}_{2} \mathrm{H}_{2}\right)$ as well as carbon monoxide $(\mathrm{CO})$ and water $\left(\mathrm{H}_{2} \mathrm{O}\right)$. These products were recognized in all $\mathrm{N}_{2}: \mathrm{CH}_{4}: \mathrm{CO}_{2}$ gas mixtures. The products concentrations are strongly dependent on the composition of the gas mixtures.

Relative quantifications of selected hydrocarbons were done in dependence on the methane concentration and gas mixture flow rate. The relative intensity was calculated as an area under the recorded peaks. Figures 4 and 5 shows dependences of the calculated relative hydrocarbon intensity on carbon dioxide additions and discharge current. Figure 4 shows the quantitative analysis of $\mathrm{HCN}\left(1430 \mathrm{~cm}^{-1}\right)$ and Figure $5 \mathrm{NH}_{3}\left(966 \mathrm{~cm}^{-1}\right)$ formed under different experimental conditions. The increase of the initial discharge current from $15 \mathrm{~mA}$ to $40 \mathrm{~mA}$ leads to increase in the product yield of this compound. The admixture of $1 \%$ $\mathrm{CO}_{2}$ had little influence on $\mathrm{HCN}$ and $\mathrm{NH}_{3}$ production. However, there is visible effect of $\mathrm{CO}_{2}$ addition to nitrogen methane mixtures with $1 \%$ methane with the yield of $\mathrm{HCN}$ increasing with increasing $\mathrm{CO}_{2}$ concentrations. This is in contrast to earlier study [22] that suggested that the kinetics of $\mathrm{HCN}$ formation slows down in presence of $\mathrm{CO}$, showing an inhibiting role of $\mathrm{CO}$ on $\mathrm{HCN}$ formation.

\section{Conclusion}

The gaseous phase products formed in the atmospheric glow discharge fed by different mixtures of nitrogen plus methane $(1 \%$ and $3 \%)$ and admixture of carbon dioxide (1,2 and $3 \%$ ) were determined by in situ FTIR and GC-MS analysis. The discharge was operated in the flowing regime at different discharge currents at laboratory temperature. An in-situ FTIR technique for the exhaust gas phase sampling was successfully used for chemical analysis to deduce the gas composition in the $\mathrm{N}_{2}: \mathrm{CH}_{4}: \mathrm{CO}_{2}$ reactive gas mixture mimics of Titan's atmosphere. Various nitrile compounds and hydrocarbons were observed in all experiments. HCN was identified as the major gas phase product in all of measurements. Others minor products detected were $\mathrm{C}_{2} \mathrm{H}_{2}, \mathrm{NH}_{3}, \mathrm{CO}_{2}, \mathrm{CO}$ and also some nitrile oxides. These results are consistent with the Titan's atmospheric composition because the 


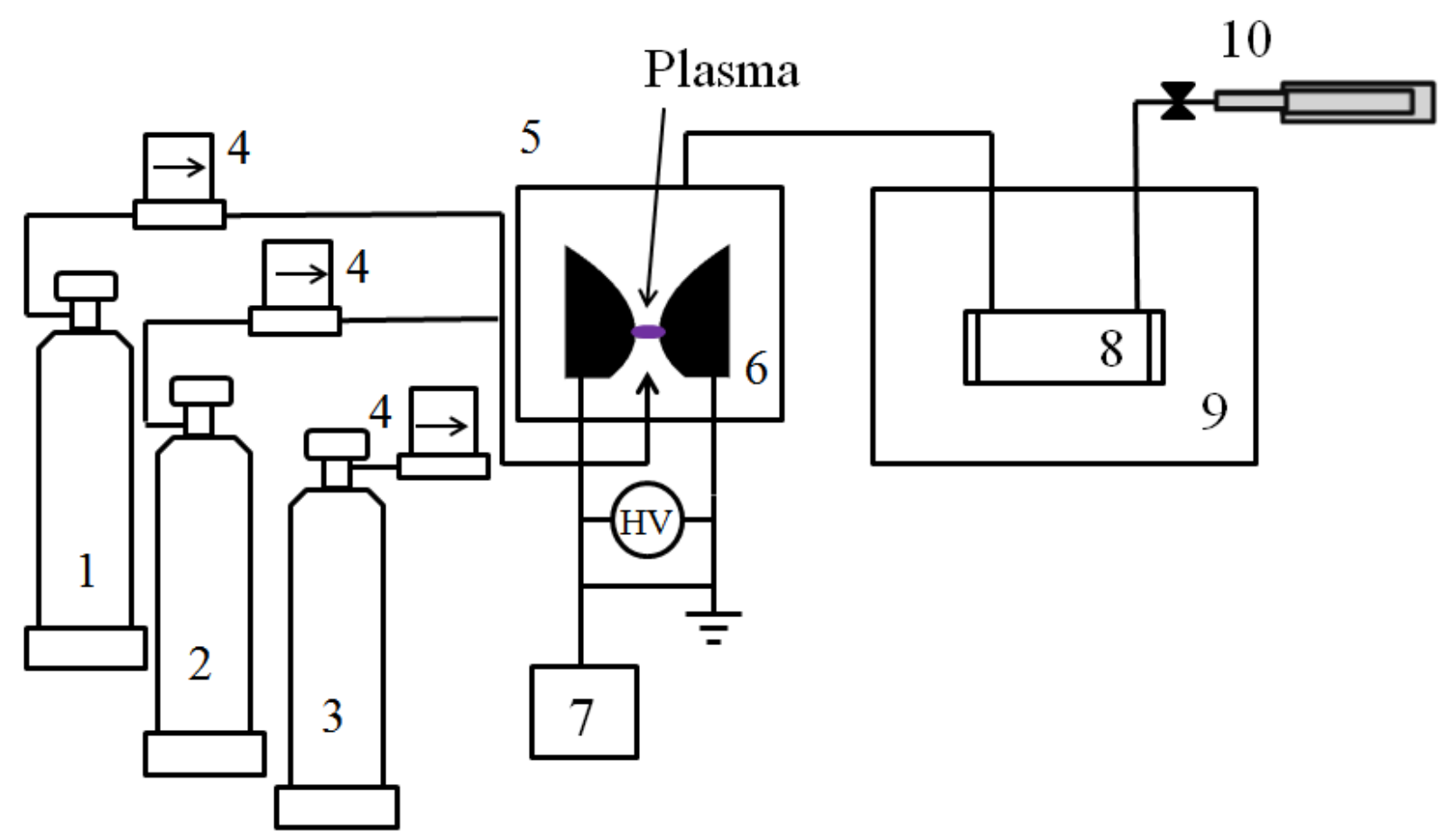

Figure 1. Experimental setup. 1- storage bottle of nitrogen, 2- storage bottle of methane, 3- storage bottle of carbon dioxide, 4- Bronkhorst controllers, 5- reactor body, 6- electrode system, 7- oscilloscope, 8- IR gas cell, 9- FTIR spectrometer, 10- cold trap.

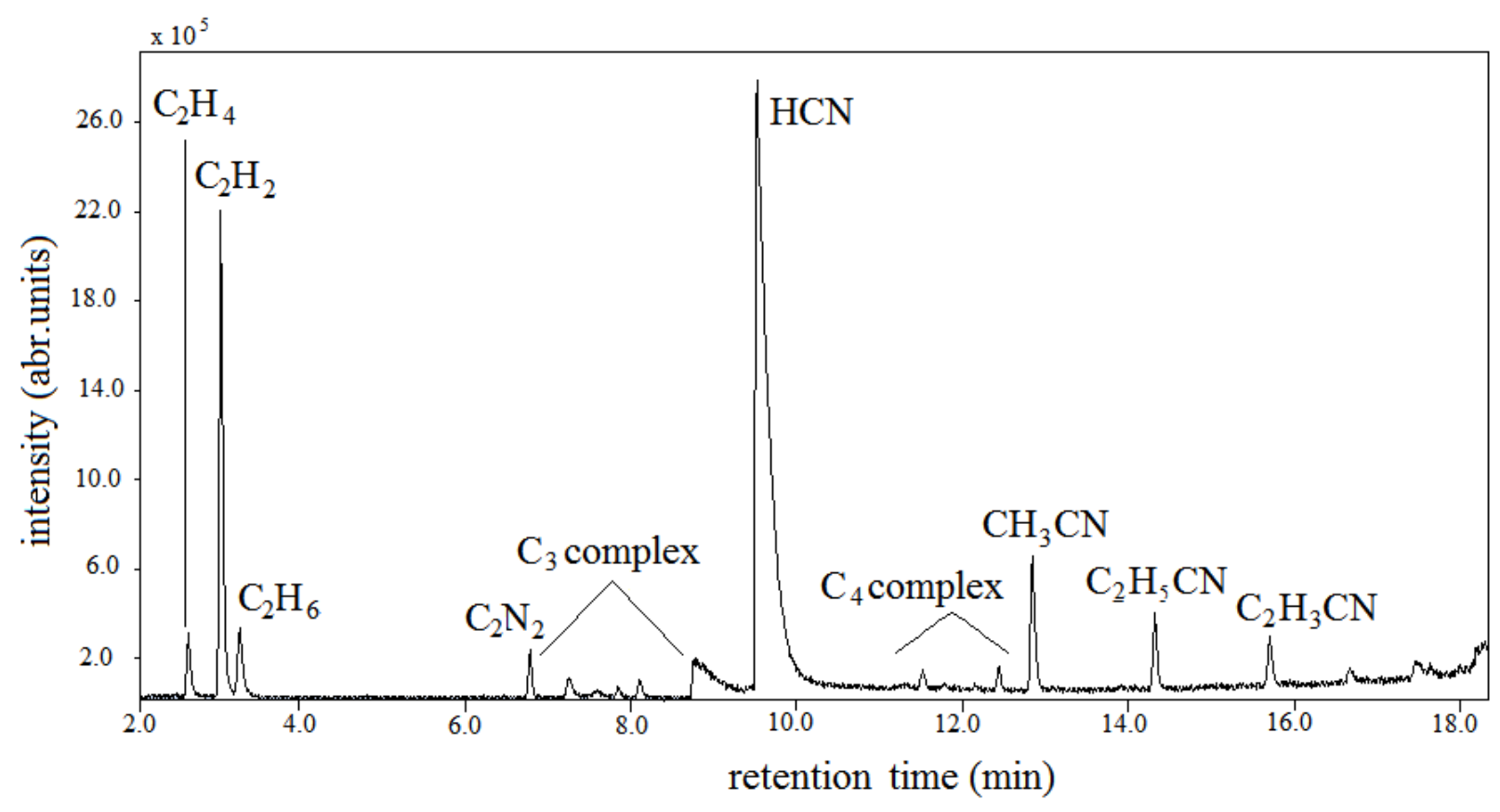

Figure 2. An example of exhaust gas chromatogram in $98 \% \mathrm{~N}_{2}: 1 \% \mathrm{CH}_{4}: 1 \% \mathrm{CO}_{2}$ gas mixture. 


\begin{tabular}{lllllll}
\hline \hline & \multicolumn{3}{c}{$1 \%$ of $\mathrm{CH}_{4}$ concentration } & \multicolumn{3}{c}{$3 \%$ of $\mathrm{CH}_{4}$ concentration } \\
\hline concentration of $\mathrm{CO}_{2}(\%)$ & 0 & 1 & 2 & 0 & 1 & 2 \\
\hline acetylene & $1.45 \times 10^{6}$ & $1.72 \times 10^{6}$ & $2.12 \times 10^{6}$ & $1.79 \times 10^{6}$ & $2.77 \times 10^{6}$ & $3.33 \times 10^{6}$ \\
ethene & $1.94 \times 10^{5}$ & $2.63 \times 10^{5}$ & $3.02 \times 10^{5}$ & $2.69 \times 10^{5}$ & $3.19 \times 10^{5}$ & $3.24 \times 10^{5}$ \\
ethane & $4.35 \times 10^{4}$ & $5.39 \times 10^{4}$ & $7.04 \times 10^{4}$ & $5.36 \times 10^{5}$ & $6.19 \times 10^{5}$ & $7.44 \times 10^{5}$ \\
hydrogen cyanide & $8.87 \times 10^{6}$ & $1.82 \times 10^{7}$ & $2.26 \times 10^{7}$ & $2.89 \times 10^{7}$ & $3.43 \times 10^{7}$ & $5.08 \times 10^{7}$ \\
acetonitrile & $9.28 \times 10^{5}$ & $1.86 \times 10^{6}$ & $3.43 \times 10^{6}$ & $2.15 \times 10^{6}$ & $2.70 \times 10^{6}$ & $3.60 \times 10^{6}$ \\
cyanogen & $2.81 \times 10^{5}$ & $4.23 \times 10^{5}$ & $8.06 \times 10^{5}$ & $4.15 \times 10^{5}$ & $6.16 \times 10^{5}$ & $8.26 \times 10^{5}$ \\
\hline \hline
\end{tabular}

Table 1. The list of selected compounds from GC-MS analysis. The relative intensity was calculated as an area under the recorded peaks (arbitrary unit).

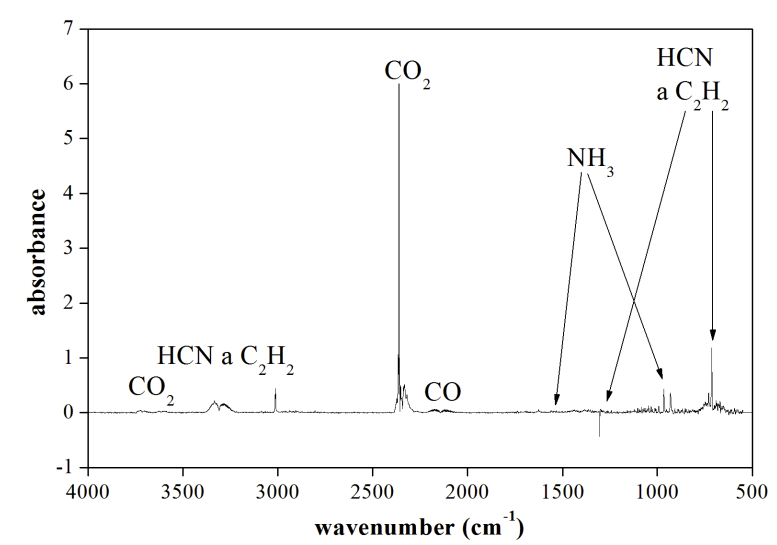

Figure 3. An example of IR spectrum in $98 \% \mathrm{~N}_{2}: 1 \%$ $\mathrm{CH}_{4}: 1 \% \mathrm{CO}_{2}$ gas mixture.

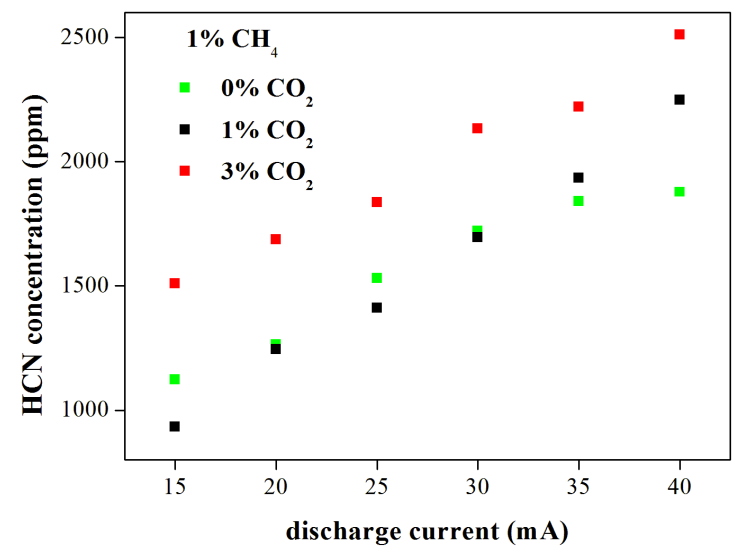

Figure 4. The dependence of hydrogen cyanide concentration on discharge current for different initial concentration of methane and carbon dioxide.

same compounds were detected during the CassiniHuygens space mission. CO could have an effect on the atmospheric reactivity of Titan. The formation of organic molecules incorporating oxygen in gases could occur in the upper atmosphere of Titan where the dissociations of $\mathrm{N}_{2}$ and $\mathrm{CO}_{2}$ by VUV photons and magnetospheric electrons are possible. This fact clearly demonstrates that laboratory experiments can

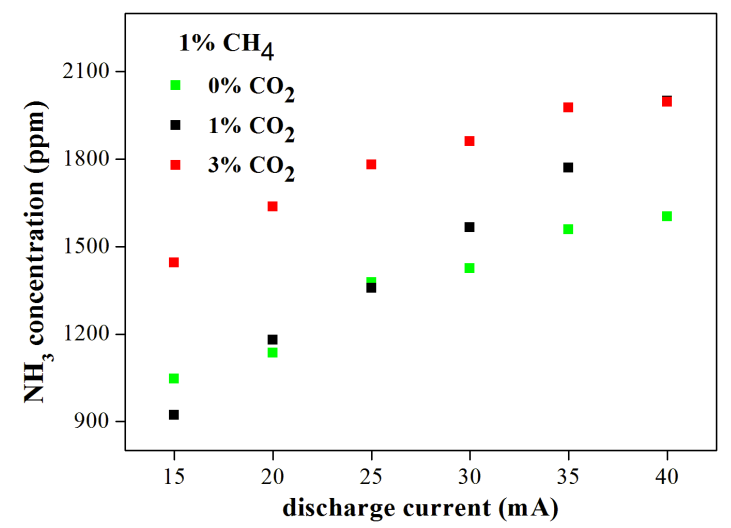

Figure 5. The dependence of ammonia concentration on discharge current for different initial concentration of methane and carbon dioxide.

be used for prediction of both the presence and possible concentrations of compounds which have not been detected, yet. These simple organics should be tracers of the chemical groups constituting the dusty products.

\section{Acknowledgements}

The research was supported by Czech Ministry of Education, Youth and Sports, projects No. COST CZ LD15011, within the collaboration of the COST Action TD 1308, CEEPUS network AT-0063.

\section{References}

[1] C.A. Nixon. Detection of propene in Titan's stratosphere. Astrophys J, 776(1), 2013.

[2] V.A. Krasnopolsky. Chemical composition of Titan's atmosphere and ionosphere: Observations and the photochemical model. Icarus, 236:83-91, 2014.

[3] K.L. Aplin. Atmospheric electrification in the solar system. Surveys in Geophysics, 27(1):63-108, 2006.

[4] S. Vinatier. Vertical abundance profiles of hydrocarbons in titan's atmosphere at 15 degrees s and 80 degrees $\mathrm{n}$ retrieved from CASSINI/CIRS spectra. Icarus, 188(1):120-138, 2007.

[5] R. Navarro Gonzalez. Corona discharge of titan's troposphere. Life Sciences: Complex Organics in Space, pages 1121-1133, 1997. 
[6] M.L. Cable. Titan tholins: Simulating titan organic chemistry in the cassini-huygens era. Chemical Reviews, 112(3):1882-1909, 2012.

[7] S.L. Miller. A production of amino acids under possible primitive earth conditions. Science, 117(3046):528-609, 1953.

[8] G. Horvath. Methane decomposition leading to deposit formation in a dc positive ch4-n2 corona discharge. Plasma Chemistry and Plasma Processing, 31(2):327-335, 2011.

[9] S.I. Ramirez. Organic chemistry induced by corona discharges in titan's troposphere: Laboratory simulations. Space Life Sciences, 36(2):274-280, 2005.

[10] C. Szopa. Pampre: A dusty plasma experiment for titan's tholins production and study. Planetary and Space Science, 54(4):394-404, 2006.

[11] E. Sciamma-O'Brien. The titan haze simulation experiment on cosmic: Probing titan's atmospheric chemistry at low temperature. Icarus, 243(0):325-336, 2014 .

[12] P. Lavvas. Aerosol growth in titan's ionosphere. Proceedings of the National Academy of Sciences, 110(8):2729-2734, 2013.

[13] R. Navarro-Gonzalez. Production of hydrocarbons and nitriles by electrical processes in titan's atmosphere. Space Life Sciences, 27(2):271-282, 2001.

[14] G. Horvath. Packed bed dbd discharge experiments in admixtures of $\mathrm{n} 2$ and ch4. Plasma Chemistry and Plasma Processing, 30(5):565-577, 2010.

[15] J.M. Bernard. Experimental simulation of titan's atmosphere: Detection of ammonia and ethylene oxide. Planetary and Space Science, 51(14):1003-1011, 2003.

[16] J.M. Bernard. Reflectance spectra and chemical structure of titan's tholins: Application to the analysis of cassini-huygens observations. Icarus, 185(1):301-307, 2006 .

[17] C.D. Pintassilgo. Methane decomposition and active nitrogen in a n2-ch4 glow discharge at low pressures. Plasma Sources Science and Technology, 8(3):463-478, 1999.

[18] Y. Sekine. The role of organic haze in titan's atmospheric chemistry i. laboratory investigation on heterogeneous reaction of atomic hydrogen with titan tholin. Icarus, 194(1):186-200, 2008.

[19] T. Gautier. Nitrile gas chemistry in titan's atmosphere. Icarus, 213(2):625-635, 2011.

[20] H. Imanaka. Laboratory experiments of titan tholin formed in cold plasma at various pressures:

Implications for nitrogen-containing polycyclic aromatic compounds in titan haze. Icarus, 168(2):344-366, 2004.

[21] U.S. Department of Commerce. 2009 National institute of standards and technology.

[22] B. Fleury. Influence of co on titan atmospheric reactivity. Icarus, 238(0):221-229, 2014. 